\title{
ADOLESCÊNCIA, DESENVOLVIMENTO MORAL E EDUCAÇÃO: CONSIDERAÇÕES A PARTIR DO DESENHO ANIMADO CAVERNA DO DRAGÃO
}

Lucian da Silva Barros*

\begin{abstract}
RESUMO: O texto apresenta os resultados de uma pesquisa com foco no desenvolvimento moral do adolescente. O desenho animado Caverna do Dragão foi tomado como objeto de estudo, a partir do qual, por meio das ações expressas por seus personagens nos episódios, buscamos os subsídios necessários para a construção de uma reflexão a respeito de como o adolescente vivencia, em seu cotidiano, os mais diversos dilemas morais, e os meios que aplica no enfrentamento e resolução dessas questões. Após a análise dos dados, realizou-se uma aproximação dessa proposta com o contexto escolar, buscando construir estratégias de atuação na escola.
\end{abstract}

PALAVRAS-CHAVE: Desenvolvimento moral; adolescência; valores; desenho de animação.

\section{ADOLESCENCE, MORAL DEVELOPMENT AND EDUCATION: CONSIDERATIONS FROM THE ANIMATED FEATURE DUNGEONS \& DRAGONS}

\begin{abstract}
The text presents the results of a research focusing on the adolescent's moral development. The cartoon Dungeons \& Dragons was taken as study object, from which, through the actions of its characters, the necessary subsidies were sought for the construction of a reflection, regarding how teenagers experience in their daily lives the most diverse moral dilemmas and the means they apply in dealing with and resolving these issues. After analyzing the data, this proposal was approached with the school context, seeking to build performance strategies in the school.
\end{abstract}

KEYWORDS: Moral development; adolescence; values; animated drawing.

\section{Introdução}

A adolescência é um tema complexo e muitas vezes difícil de ser abordado. Ora encarada como um período de transição permeado de dilemas e problemáticas, ora vista como uma das melhores fases da vida humana, esta é, sem dúvida, uma etapa muito importante do desenvolvimento humano, na qual o tornar-se adulto parece algo inevitável.

Existem inúmeras tentativas de se definir o conceito de adolescência, embora nem todas as sociedades concordem com a sua existência. Cada cultura possui uma forma distinta de demarcar esse

\footnotetext{
* Mestre em educação pela USCS; Psicólogo formado pela UNISANTOS; Especialista em Ética, valores e cidadania na escola pela USP; Professor do SENAC-SP. E-mail: lucian.barros@hotmail.com

ORCID: https://orcid.org/0000-0001-7592-3473
} 
momento, baseando-se em fatores, como crenças religiosas, estilos de vida, entre outros. É possível dizer que a adolescência é um período do ciclo vital, caracterizado por profundas mudanças, de ordem física, social e psicológica.

No Brasil, o Estatuto da Criança e do Adolescente (BRASIL, 1990) define esta fase como característica dos doze aos dezoito anos de idade, na qual crianças e adolescentes são sujeitos de direitos. Conforme o Estatuto, eles detêm o direito à vida, à saúde, à alimentação, à educação, ao esporte, ao lazer, à profissionalização, à cultura, à dignidade, ao respeito, à liberdade e à convivência familiar e comunitária, os quais devem ser sempre preservados. A Organização Mundial de Saúde (OMS) concebe a adolescência como o período que vai dos dez aos dezenove anos de idade

A adolescência, por sua vez, pode ser tomada como uma atitude cultural, ou postura do ser humano durante uma fase de seu desenvolvimento, que reflete as expectativas da sociedade sobre este grupo. Nesta visão, a adolescência surge como um papel social, como um processo de passagem percorrido pelo indivíduo entre o período das atividades infantis e a sua plena integração ao grupo produtivo e reprodutor.

Pensar nas características do adolescente implica tomar o seu desenvolvimento de maneira global e buscar compreender o modo pelo qual constrói seus valores, seus julgamentos e suas ações. Valores como justiça, dignidade, respeito, tolerância e igualdade podem ser aprendidos pelos jovens em suas famílias, nas igrejas, na rua e em todos os contextos e espaços onde convive e estabelece relações. A convivência com os adultos e com os amigos, o contato com os meios de comunicação e a observação da vida cotidiana contribuem para a formação moral do adolescente de maneira significativa.

A moralidade tornou-se, dentro do campo das ciências humanas e sociais, um tema de destaque, o qual sempre suscitou diversas indagações e especulações. A psicologia, como ciência que estuda o humano, tem encontrado no estudo da moralidade um vasto campo de investigação e atuação, um campo que visa preencher lacunas, até então abertas, a respeito das ações humanas. A psicologia moral nasce como uma tentativa de compreensão da construção da moralidade inserida na subjetividade, compreendendo também as influências desta moralidade na estruturação da personalidade e da identidade de cada sujeito.

Segundo La Taille (2006b), a psicologia moral é uma ciência preocupada em desvendar por quais processos mentais uma pessoa chega a intimamente legitimar, ou não, regras, princípios e acima de tudo, valores morais. Compreender de forma mais clara os passos para a construção da personalidade moral humana, possibilita pensar em intervenções que facilitem e promovam a formação de personalidades éticas em crianças e adolescentes, tendo sempre como meta a constituição de uma sociedade cada vez mais justa, solidária e igualitária.

O objetivo deste trabalho é fazer uma análise do desenvolvimento moral do adolescente tendo como base a manifestação das virtudes, destacadamente três delas: a coragem, a justiça e a generosidade. Como objeto de estudo, elegeu-se o desenho animado Caverna do Dragão (Dungeons \& Dragons), buscando 
realizar uma análise psicológica desta animação e do desenvolvimento moral de seus personagens, analisando as tomadas de decisões realizadas no enfretamento dos dilemas morais apresentados no enredo da história. Buscou-se, ainda, verificar as possibilidades de aplicação prática do desenho no contexto escolar, objetivando despertar nos adolescentes, principalmente do Ensino Médio, a manifestação das virtudes e dos sentimentos morais.

O desenho animado, criado na década de 1980 nos EUA, apresenta a história de seis jovens, uma criança e cinco adolescentes, perdidos em um mundo mágico, que buscam encontrar o caminho de volta para casa. Ao longo dos episódios, os jovens vivenciam situações de conflito e experimentam certas ambiguidades em suas tomadas de decisões que podem ser consideradas como dilemas morais. Há, no transcorrer de todo o desenho e, principalmente devido a estas situações emblemáticas, a manifestação, por parte dos personagens, de diversos sentimentos e valores, considerados de alto teor moral.

Neste sentido, questionou-se ser possível realizar uma tentativa de aproximação entre as diversas características de personalidade dos principais personagens do desenho, assim como também dos sentimentos e valores manifestados por estes ao longo da história, com as principais teorias que abordam o desenvolvimento da personalidade moral humana. Com base nisso. o presente trabalho propõe-se a responder a seguinte questão: Os personagens do desenho animado Caverna do Dragão, por serem adolescentes na história, apresentam as virtudes, da coragem, da justiça e da generosidade em suas personalidades como as encontradas no desenvolvimento moral humano?

Este estudo insere-se na área da psicologia moral e nas suas interconexões com a área da psicologia do desenvolvimento, em especial no que tange a compreensão do desenvolvimento psicossocial do adolescente. Elegeram-se como principais referenciais teóricos deste trabalho as contribuições da epistemologia genética proposta por Jean Piaget e os estudos realizados por seus principais seguidores ao longo das últimas décadas nos campos do desenvolvimento cognitivo e moral.

\section{Fundamentação teórica}

O marco da teoria piagetiana sobre o desenvolvimento da moral está na publicação do livro $O$ Juízo Moral na Criança, no qual Piaget (1994) buscou descrever como o indivíduo constrói seu raciocino e conduta moral. Apesar da extensa obra de Piaget, este é seu único livro que trata do desenvolvimento da moralidade humana, sendo este tema, como será apontado a seguir, aprofundado por seus seguidores.

Para Piaget (1994), o desenvolvimento da moral humana passa por três fases: a da anomia, a da heteronomia, concebida como a moral do dever, e a da autonomia, esta entendida pelo autor, como a moral do bem. La Taille (2006b) relata que a fase da anomia “[...] corresponde ao estágio do desenvolvimento durante o qual a criança ainda não adentrou o universo moral” (p. 97), caracterizando-se pela total ausência de regras, ou melhor, a prática das regras é atrelada nesta fase exclusivamente ao aspecto motor, à satisfação motora da criança, não ocorrendo, portanto, consciência em relação a existência de tais regras (grifo nosso). 
Ainda segundo La Taille (2006b), Piaget divide o desenvolvimento da moral humana em tendências gerais, atestando para a existência de apenas duas morais, uma da heteronomia e outra da autonomia. De acordo com o autor, o pesquisador suíço não fala em estágios do desenvolvimento moral, mas sim em tendências que guiam os sujeitos em seus modos de agir. A referência de Piaget por tendências está ligada ao fato de que durante a vida humana, ambas as tendências (heteronomia e autonomia) estão sempre presentes, ora prevalecendo uma, ora prevalecendo outra, dependendo sempre do nível de desenvolvimento e aprendizagem de cada indivíduo, a partir de suas relações sociais.

Menin (1996) atesta que, para Piaget, a moral decorre do respeito que cada indivíduo adquire pelas regras. Segundo a autora, este respeito inicia-se primeiramente no respeito às pessoas que impõem as regras, já que, como destaca "Primeiro respeitamos pessoas, depois regras" (p. 50). Há, como aponta, dois tipos distintos de respeito por pessoas: o respeito unilateral e o respeito mútuo.

O quadro 1 apresenta as relações existentes entre o desenvolvimento cognitivo e o desenvolvimento do juízo moral na obra de Piaget, destacando as principais características deste último.

Quadro 1 - Desenvolvimento do juízo moral por Piaget

\begin{tabular}{|c|c|c|}
\hline PERÍODOS & $\begin{array}{l}\text { DESENVOLVIMENTO } \\
\text { COGNITIVO } \\
\end{array}$ & JUÍZO MORAL \\
\hline $\begin{array}{l}\text { SENSÓRIO- } \\
\text { MOTOR } \\
0 \text { a } 2 \text { anos }\end{array}$ & Inteligência de ordem prática & Anomia; não há sentido de moralidade \\
\hline $\begin{array}{l}\text { PRÉ- } \\
\text { OPERATÓRIO } \\
2 \text { a } 7 \text { anos }\end{array}$ & $\begin{array}{l}\text { Aparecimento da função simbólica e } \\
\text { desenvolvimento da linguagem }\end{array}$ & $\begin{array}{l}\text { Heteronomia; moral baseada no medo de } \\
\text { represália; obediência à autoridade }\end{array}$ \\
\hline $\begin{array}{l}\text { OPERATÓRIO } \\
\text { CONCRETO } \\
7 \text { a } 12 \text { anos }\end{array}$ & Pensamento racional e lógico & $\begin{array}{l}\text { Heteronomia; moral baseada no respeito } \\
\text { unilateral e na reciprocidade; crianças seguem as } \\
\text { regras e esperam que todos façam o mesmo }\end{array}$ \\
\hline $\begin{array}{l}\text { OPERATÓRIO } \\
\text { FORMAL } \\
12 \text { anos em diante }\end{array}$ & $\begin{array}{l}\text { Capacidade de abstração, } \\
\text { simultaneidade e metapensamento }\end{array}$ & $\begin{array}{l}\text { Autonomia; moral baseada em princípios } \\
\text { superiores de leis e no respeito mútuo; equidade } \\
\text { e cooperação; reconhecimento de que as regras } \\
\text { podem ser mudadas }\end{array}$ \\
\hline
\end{tabular}

Fonte: D’Aurea-Tardeli, 2007, p. 25 (adaptação nossa).

De acordo com La Taille (2006b), o adolescente para Piaget não é um indivíduo totalmente autônomo, mas que apresenta características de autonomia moral, justamente por ser capaz de legitimar algumas regras morais, tendo como principal referência as suas figuras de autoridade. La Taille destaca, ainda, que o desenvolvimento moral, assim como os demais, é visto pelo teórico suíço como fruto de uma construção, de uma constante auto-regulação do indivíduo no contato com seu meio, sendo que a 
construção da autonomia moral, como já apontado acima, só é possível de acontecer em ambientes de interação social em que predominem práticas e ações cooperativas.

A ampliação de teorias de Piaget a respeito da moral coube a seus seguidores, destacadamente o psicólogo norte-americano Lawrence Kohlberg. Segundo La Taille (2002), a teoria de Kohlberg é considerada por muitos como uma expressão mais sofisticada dos princípios cunhados por Piaget a respeito do desenvolvimento moral. Kohlberg, diferentemente de Piaget, que tomava a moral como tendências, define estágios fixos para o desenvolvimento moral, nos quais todos os seres humanos se encontrariam em algum momento.

Kohlberg dá continuidade às pesquisas de Piaget, ampliando o universo etário de suas amostras não se restringe apenas ao estudo com crianças - e ainda aperfeiçoando as técnicas de entrevista clínica utilizadas pelo autor suíço. O pesquisador norte-americano utiliza-se em suas pesquisas de histórias hipotéticas, denominadas de dilemas morais ${ }^{1}$, os quais são destinados a provocar a manifestação da estrutura do juízo moral desenvolvido por cada sujeito entrevistado.

O resultado dos estudos de Kohlberg é o desmembramento das etapas do desenvolvimento do juízo moral propostas por Piaget em seis diferentes estágios. Estes estão agrupados em três níveis básicos do desenvolvimento moral em uma faixa etária que se estende até depois dos vinte anos de idade. Os três níveis básicos, propostos pelo autor, são: o pré-convencional, o convencional e o pós-convencional.

Cada nível comporta, em si, dois diferentes estágios passíveis de serem resumidos da seguinte forma: no nível pré-convencional, estágios 1 e 2 (1 - orientação para a punição e a obediência; 2 orientação instrumental-relativista); no nível convencional, estágios 3 e 4 (3 - a concordância interpessoal ou orientação para o "bom menino-boa menina"; 4 - orientação para a manutenção da sociedade); e, por fim, no nível pós-convencional, estágios 5 e 6 (5 - orientação para o contrato social; 6 - orientação para o princípio ético universal). (LA TAILLE, 2006b, p. 101-103)

Coube à pesquisadora norte-americana Carol Gilligan a responsabilidade de trazer ao campo da psicologia moral as primeiras críticas a respeito da diferença entre homens e mulheres, no que tange ao desenvolvimento da moralidade. Gilligan questiona basicamente o princípio de justiça como a única fonte possível de construção da moralidade (LA TAILLE, 2002). De modo ainda bastante resumido, é possível dizer que a pesquisadora defende a existência de duas orientações morais distintas: a da ética do cuidado, está mais presente nos juízos das mulheres; e a da ética da justiça, que domina os juízos dos homens.

Gilligan toma a categoria gênero como aspecto importante de análise no desenvolvimento da gênese da moral, por duas razões: a primeira refere-se à condição da mulher na sociedade, de caráter subalterno ao dos homens; e a segunda recai em termos metodológicos de aplicação dos dilemas morais, já que considera que os conteúdos presentes nestes dilemas, até então utilizados pelos pesquisadores da

\footnotetext{
${ }^{1}$ La Taille (2006b) destaca que Piaget em seu método clínico de investigação dos julgamentos morais de crianças, destacadamente do surgimento da noção de justiça, utiliza-se também da aplicação de dilemas morais, porém de complexidade mais simples que os empregados por Kohlberg.
} 
moral, não são relativos à realidade da mulheres, dificultando o processo de identificação, necessário às pesquisas, com as personagens envolvidas neles: eram basicamente dilemas feitos por homens para homens.

Outra corrente teórica que também contribuiu para a produção de um novo enfoque no estudo da moralidade é formada por autores interessados em investigar o raciocínio pró-social. Koller e Bernardes (1997) consideram que o desenvolvimento moral pró-social de um indivíduo refere-se ao processo de aquisição e mudança dos julgamentos e comportamentos relacionados à ajuda ou benefício dirigidos a outros indivíduos ou mesmo grupos. O movimento pró-social caracteriza-se, como salientam as autoras, por ações ou julgamentos voluntários, definidos dentro de um contexto e expressos sempre em termos de suas consequências positivas. Estas autoras destacam, ainda, que a motivação básica da pró-sociabilidade consiste em beneficiar o outro, sem influências ou pressões externas ou, ainda, sem expectativas de prêmios ou recompensas materiais ou sociais. Em síntese, a pró-sociabilidade é um aspecto humano que pode se manifestar, por meio de intenções, ações ou mesmo pela expressão verbal do raciocínio sobre um dilema moral experimentado nas experiências cotidianas de cada indivíduo. (KOLLER; BERNARDES, 1997, p. 224)

Nesta abordagem, destacam-se as contribuições de Nancy Eisenberg, pesquisadora norteamericana da Universidade do Estado do Arizona, contemporânea a Kohlberg e Gilligan, que desenvolveu um modelo teórico e metodológico de avaliação do raciocínio pró-social. Koller e Bernardes (1997) relatam que, em 1977, Eisenberg defendeu a sua tese de doutorado, na qual realizou um estudo de caráter transversal, que tinha por objetivo examinar as diversas mudanças evolutivas no raciocínio de crianças sobre dilemas pró-sociais.

A respeito da relação entre as teorias das duas pesquisadoras apresentadas, La Taille (2006a) afirma que Gilligan, em suas teses, procurou deslocar o eixo das pesquisas da justiça para o cuidado, dando ênfase a uma diferenciação no desenvolvimento moral de homens e mulheres. Por outro caminho, a abordagem do desenvolvimento proposta por Eisenberg traz como proposição principal, uma oposição entre deveres negativos e deveres positivos na busca de atitudes pró-sociais.

As proposições de Gilligan e Eisenberg são de extrema importância na configuração deste trabalho, que visa investigar o desenvolvimento da personalidade moral do adolescente e a emergência e exercício das virtudes, não se restringindo apenas à justiça como valor por excelência, mas indo em direção da generosidade e de outras virtudes tidas como mais subjetivas e que podem se manifestar de diversas maneiras frente às situações conflituosas.

\section{Metodologia}

Buscamos realizar, neste artigo, um estudo qualitativo de caráter exploratório, tendo como delineamento a pesquisa bibliográfica, que visa analisar o desenvolvimento moral e a manifestação das 
virtudes em adolescentes e que tem, por objeto, o estudo do desenho animado Caverna do Dragão (Dungeons \& Dragons), e a análise de dois personagens da série.

Os personagens analisados nesta pesquisa foram os jovens Presto e Eric, ambos do sexo masculino e que, na história apresentada no desenho, aparentam ter quatorze anos de idade. A seguir, segue uma rápida apresentação destes personagens:

Eric, o cavaleiro (Cavalier), de quatorze anos, que recebe um poderoso escudo inquebrável, é o jovem mais instável de todo grupo, extremamente medroso, que tenta a todo custo voltar para casa, mas acaba desistindo por conta de seus amigos. Sempre questiona as instruções do Mestre dos Magos, mas sem obter respostas. É proveniente de uma família de classe média alta. Pela característica de sua arma mágica, é ele quem sempre acaba protegendo os outros dos ataques dos inimigos. Apresenta grande implicância com as mágicas desastradas de Presto, e também com Bobby e Uni, e seu maior medo é ser motivo de piada.

Presto, o mago (Magician), também de quatorze anos, recebeu um chapéu de feiticeiro, do qual podem ser retirados diversos objetos, e ainda realizar mágicas. Por sua aparência física e o uso de óculos, pode ser considerado o típico nerd, apresentando muita dificuldade para lidar com a sua arma mágica. Expressa, durante a história, certa vontade de ficar no reino, pois se sente mais aceito e valorizado do que no seu próprio mundo. Forma, juntamente com Eric, e apesar das constantes brigas, uma engraçada dupla, e o seu maior medo é perder os óculos e não conseguir enxergar.

A escolha dos dois personagens seguiu como critério o fato de estes serem considerados como os que, durante a série, obtinham maior destaque em suas ações e melhor representavam a fase da adolescência.

Para cada personagem, foi selecionado um episódio no qual estes apareciam como destaques e enfrentavam dilemas morais. Buscou-se, portanto, a partir das tomadas de decisão dos personagens nos episódios, verificar o desenvolvimento moral e a manifestação das virtudes nas ações dos personagens, a saber:

- PRESTO - Episódio 1: A Noite Sem Manhã.

- $\quad$ ERIC - Episódio 6: A Bela e a Fera do Pântano.

O estudo iniciou-se com a revisão completa dos vinte e sete episódios da série, os quais se encontram disponíveis para visualização na internet, no site YouTube.

Esta revisão teve como objetivos: fazer um levantamento prévio dos dados; verificar a existência de dilemas morais no decorrer da história; e auxiliar na escolha dos personagens para análise.

A seleção dos personagens e dos episódios apresentados acima foi realizada após esta revisão, sendo destacados os dilemas morais mais emergentes em cada personagem, ou seja, aqueles mais claramente percebidos e também considerados mais significativos por requererem dos jovens uma tomada de decisão mais refletida e contextualizada. O estudo seguiu-se primeiro com a análise do personagem Presto e, na sequência, com a do personagem Eric. 
O levantamento dos dilemas enfrentados pelos personagens teve como padrão os aspectos relacionados a uma situação de dilema moral ${ }^{2}$, da qual foi possível elencar três critérios de análise para a verificação de sua existência:

a) apresentar situação dilemática, que requer do indivíduo uma tomada de decisão;

b) a situação apresentada deve conter em si duas ou mais soluções, sem que haja em um primeiro momento uma considerada como certa e outra errada; e

c) possibilitar ao indivíduo a realização de um julgamento livre sem imposições ou mesmo pressões externas explícitas.

A análise dos episódios e dos dilemas morais enfrentados pelos personagens seguiu o roteiro apresentado no quadro 2.

Quadro 2 - Roteiro de análise dos episódios

\begin{tabular}{|c|c|}
\hline Episódio: & Número / Nome do episódio \\
\hline Personagem em destaque: & Nome do personagem. \\
\hline Dilema moral: & Dilema moral apresentado ao personagem. \\
\hline Resolução do dilema: & $\begin{array}{l}\text { Contextualização da situação. Tomada de decisão do personagem. } \\
\text { Conscientização sobre a decisão tomada. Desdobramento das atitudes. }\end{array}$ \\
\hline $\begin{array}{l}\text { Virtude principal do } \\
\text { personagem: }\end{array}$ & Virtude que se manifesta com mais clareza \\
\hline $\begin{array}{l}\text { Virtude secundária do } \\
\text { personagem: }\end{array}$ & Presença de outras virtudes. \\
\hline Manifestação das virtudes: & $\begin{array}{l}\text { Estudo sobre a virtude manifesta e a verificação da evolução do } \\
\text { desenvolvimento moral do personagem. }\end{array}$ \\
\hline $\begin{array}{l}\text { Aspectos relacionados ao } \\
\text { desenvolvimento moral: }\end{array}$ & $\begin{array}{c}\text { Análise da correspondência entre o desenvolvimento dos personagens com as } \\
\text { fases descritas pelos teóricos do desenvolvimento moral. }\end{array}$ \\
\hline
\end{tabular}

Fonte: $\mathrm{O}$ autor

A elaboração deste roteiro teve como objetivo sistematizar os dados coletados nos episódios, tornando-os mais claros e consistentes, o que possibilitou a visualização mais contextual de alguns pontos importantes para este estudo, dentre os quais se destacam: os dilemas morais enfrentados pelos protagonistas nos episódios e os aspectos relacionados à resolução destes; a manifestação das virtudes desencadeadas nas situações de conflito; e ainda a correlação das características de cada um dos

\footnotetext{
2 Segundo Vidigal (2011), na situação do dilema moral não há uma solução mais desejável de forma evidente, já que ambas alternativas apresentadas estão em grau de equivalência quanto a sua importância ou mesmo desejabilidade. Para a autora, isto acarreta no indivíduo uma dificuldade de posicionamento, pois as alternativas que se apresentam envolvem da mesma forma valores morais que necessitam de uma hierarquização frente às tomadas de decisão. O indivíduo neste processo deverá escolher qual dos dois valores tem mais importância, sempre atribuindo a este as razões de sua escolha.
} 
personagens com os aspectos descritos nas fases do desenvolvimento moral, conforme as teorias de Piaget, Kohlberg, Gilligan e Eisenberg, já referenciadas neste trabalho.

\section{Síntese dos resultados e discussões}

No episódio “A Noite Sem Manhã”, Presto enfrenta o dilema moral de Abandonar ou não os amigos para se tornar um grande mago. Este episódio apresenta, logo em seu início, a falta de habilidade de Presto com a sua arma mágica - fato recorrente em toda a série. O jovem mago mostra-se, neste episódio, como alguém que coloca constantemente em dúvida suas capacidades e sente-se desvalorizado frente ao grupo, chegando até mesmo a pensar que seus amigos estariam melhores sem ele. Por não conseguir usar adequadamente a sua arma mágica, Presto apresenta certa dificuldade em manter com o restante do grupo uma relação de igual para igual e acaba por sentir-se subestimado frente aos outros.

Com relação ao episódio analisado, inicialmente, Presto parece ficar interessado com a proposta de se tornar o sucessor de Merlin, pois isso lhe daria um grande status e, por consequência, valorização frente aos outros. Neste momento, o valor atribuído pelo jovem às suas ações parece estar apenas ligado ao alcance de benefícios próprios e à conquista de glórias pessoais, ou seja, interessa a ele tornar-se um grande mago - o maior de todo "O Reino". Isso significaria conquistar um grande poder para si. O que pode ser considerado como um ato que não está de acordo com o exercício das virtudes já que, como aponta Comte-Sponville (1999), estas dizem respeito ao modo como cada ser humano se relaciona com os seus semelhantes e se esforça para agir bem em prol do outro.

No decorrer do episódio, a virtude principal manifestada pelo personagem é, sem dúvida, a coragem, uma vez que enfrenta seus medos para ajudar seus amigos. É esta virtude, no decorrer da história, a que desencadeia o aparecimento de todas as outras e faz com que o jovem passe a agir moralmente. Comte-Sponville (1999) aponta para o fato de a coragem ser uma virtude necessária para o exercício de todas as outras, pois somente enfrentando os obstáculos de várias ordens e os diversos riscos surgidos no caminho, é que o ser humano pode permanecer ético.

No início do episódio, as ações do personagem sugerem que este ainda esteja mais ligado ao terceiro estágio do juízo moral proposto por Kohlberg (1992 apud D’AUREA-TARDELI, 2011) e denominado de Moralidade da concordância interpessoal. Porém, Presto parece caminhar para o quarto estágio, o de Orientação para a manutenção da ordem social, no qual o indivíduo considera como correto cumprir o seu dever e manter a ordem social, estando isso atrelado a um gradual desprendimento de seu egocentrismo.

Com relação ao desenvolvimento de sua pró-sociabilidade, ou seja, da capacidade de beneficiar o outro, sem influência ou pressões externas, Presto demonstra estar ainda mais próximo do terceiro nível proposto por Eisenberg, o de Orientação para aprovação interpessoal, el ou Orientação Estereotipada, no qual, segundo apontado por Koller e Bernardes (1997), o indivíduo se utiliza de considerações relacionadas a aprovação ou aceitação dos outros para justificar seus comportamentos pró-sociais (de ajudar ou não os outros). 
Dentro do proposto por Gilligan, as ações de Presto parecem coincidir com a predominância de uma orientação moral masculina, caracterizada pela ética da justiça, na qual as suas atitudes visam responder de maneira mais lógica aos problemas morais enfrentados pelo sujeito.

No episódio "A Bela e a Fera do pântano", Eric enfrenta o dilema Ajudar ou não a libertar as Feras do Pântano. Eric pode ser considerado, em um primeiro momento, um jovem imaturo, instável e pouco solidário para com os outros. Na maioria das vezes, as atitudes de Eric fazem transparecer que este leva apenas em consideração o alcance de benefícios próprios em detrimento do auxílio aos outros. Suas atitudes, de certa forma, podem ser consideradas como destoantes das atitudes dos demais jovens, já que demonstra ser o mais obstinado a encontrar o caminho de casa, nem que para tal tenha que ignorar a presença de outros personagens e, em alguns momentos, até colocá-los em risco iminente.

As constantes reclamações de Eric, principalmente com relação ao Mestre dos Magos, e o seu aparente estado de indignação pelo fato de permanecer preso no reino mágico, sem muitas esperanças de retorno ao mundo real, são, de uma maneira geral, aspectos recorrentes em todos os episódios. Em sua visão, o jovem acredita que o velho mago sabe exatamente como ajudar o grupo, porém não se esforça para mostrar de maneira mais adequada como todos realizarão a travessia.

O jovem culpa o velho mestre por permanecer perdido no reino, o que faz transparecer de forma ainda mais ressaltada a sua imaturidade. Esta imaturidade do personagem parece ser provocada por seu aparente estado de egocentrismo que, segundo Piaget (1989 apud CARRAMILLO-GOING, 1994), constitui-se como uma espécie de centralização do pensamento, traduzido por uma inocência do espírito, no sentido de uma ausência de toda relatividade intelectual e de todo sistema racional, de onde surgem as referências de compreensão lógica. O personagem transfere a responsabilidade de seus atos para terceiros e se exime de compreender ou realizar qualquer ação que posso beneficiar a todos, mantendose, mesmo que contra sua vontade, em um estado de dependência infantil, no qual espera que um adulto, ou mesmo figura de autoridade, livre-o de todo perigo.

Logo no início do episódio em questão, Eric já apresenta total descrença nos conselhos dados pelo Mestre dos Magos, colocando em dúvida se todos deveriam realmente seguir tais instruções. A capacidade de abstração de Eric parece, até este momento, prejudicada, pois o jovem não consegue ver além do que é aparente. O que pode ser uma decorrência da rigidez de seu pensamento, o qual já adota modelos pré-concebidos do que seja correto ou não, agindo sem flexibilidade e de modo pouco adaptativo.

Com relação ao dilema moral enfrentando pelo jovem neste episódio (Ajudar ou não a libertar as Feras do Pântano), é possível dizer que o personagem somente concorda em ajudar as feras, pois não encontra outro meio de voltar a ser quem ele era. Ao ajudar as feras, o jovem cavaleiro busca uma retribuição, primeiramente a de voltar a ser um humano e, segundo, encontrar o caminho de casa. É possível encontrar em suas ações um maior domínio da justiça retributiva, uma vez que visa buscar uma proporcionalidade entre as suas ações e os benefícios ou sanções que irá receber em troca delas. Segundo 
Piaget (1994), um dos aspectos da justiça retributiva é um anseio por parte do indivíduo pela reparação e uma compreensão mais subjetiva e superior das consequências do ato praticado. Eric visa um reconhecimento por sua ação, um pagamento que lhe parece justo, afinal, a seu ver, o jovem não tem nenhuma obrigação de ajudar tais criaturas.

No decorrer do episódio, a coragem parece então surgir nas ações do personagem, mesmo que ainda permeada por interesses próprios, já que ao ajudar o outro estaria também ajudando a si próprio.

As atitudes de Eric dão indícios de que o jovem permanece ainda em um estado mais heterônomo de seu desenvolvimento moral. O personagem demonstra características condizentes com as encontradas no segundo estágio do juízo moral, denominado de Orientação instrumental-relativista. Neste estágio, segundo o proposto por Kohlberg (1992 apud D'AUREA-TARDELI, 2011), estão presentes os elementos de honestidade, reciprocidade e partilha, porém compreendidos de maneira concreta e pragmática.

Eric parece caminhar, ainda que lentamente, para o nível de desenvolvimento seguinte proposto por Kohlberg, e chamado de Nível Convencional, em especial, para o terceiro estágio de Moralidade da concordância interpessoal. Com relação ao desenvolvimento de sua pró-sociabilidade, Eric demonstra estar ainda mais próximo do primeiro nível proposto por Eisenberg, o de Orientação Auto-Focada e Hedonística, no qual, segundo apontado por Koller e Bernardes (1997), as preocupações dirigem-se para consequências que são orientadas para si mesmo, mais do que para considerações morais.

Com relação à teoria de Gilligan, como já verificado na análise do personagem anterior, as ações de Eric parecem conduzi-lo no caminho da ética da justiça, porém com uma forte tendência para a ética do cuidado, na qual o cuidado e a compaixão ocupam lugar de destaque. Mesmo protegendo várias vezes os seus amigos com seu escudo mágico, Eric parece negar este papel no seio do grupo e não cobra dos amigos qualquer tipo de glória por isso.

\section{Aproximações com o contexto escolar}

Com base nas análises realizadas, é possível pensar em aproximações das situações descritas no desenho animado com o contexto escolar. Esta aproximação tem como intuito despertar nos adolescentes ações morais que privilegiem as manifestações das virtudes, assim como chamar a atenção dos professores para a importância deste tema enquanto conteúdo pedagógico. O desenho pode se configurar com uma estratégia de falar aos jovens, a respeito do tema dos valores de modo mais lúdico e acessível. Assim como a utilização de filmes no contexto educativo vem se mostrando um bom recurso didático, os desenhos também apresentam a mesma expressividade. Desta forma, o fato do desenho Caverna do Dragão ter como seus personagens principais um grupo de jovens torna esse contato com o público adolescente ainda mais próximo.

A análise dos dados levantados com esta pesquisa pode demonstrar que o desenvolvimento moral do adolescente está atrelado ao seu desenvolvimento cognitivo, no qual os avanços na capacidade de 
raciocínio moral dependem do amadurecimento das capacidades cognitivas gerais, que tomam lugar ao longo do desenvolvimento e produzem, assim, condutas morais mais maduras.

Com relação aos personagens analisados, é possível aferir que mesmo ambos tendo na série quatorze anos de idade, estes parecem não apresentar um pensamento abstrato consolidado, no qual impere o raciocínio hipotético-dedutivo. Fato este que demonstra colaborar para que apresentem tendências morais mais heterônomas em suas ações, porém, como averiguado, com indícios da autonomia ascendente, desencadeada principalmente pelas vivências a que vão sendo expostos no decorrer da série.

Os jovens são colocados em situações que requerem deles um posicionamento, no qual se coloca em jogo o bem-estar dos demais amigos ou dos personagens que vão surgindo no decorrer da série. Perante tais situações, os jovens buscam seus modos de ação a partir de diferentes fontes, visando sempre que o dano causado seja o mínimo possível. Seja embasado naquilo que já sabem, ou seja em seu próprio repertório de vida e background, ou ainda em exemplos, advindos de seus amigos ou figuras representativas, tais modos de ação e resolução de problemas se configuram como estruturas complexas de raciocínio que requerem dos jovens a avaliação de diferentes hipóteses e uso de seu pensamento abstrato. Desta forma, é possível aferir que, ao longo de seu desenvolvimento, o jovem vai criando estruturas, que lhe serão úteis para que as suas ações possam ser refletidas. É necessário então criar no cotidiano destes jovens tais situações, para que possam aprender de modo mais vivencial a lidar com momentos da vida em que seus valores serão colocados em jogo, e em que eles deverão escolher qual o melhor caminho a seguir, se o das virtudes ou não. A escola, neste quadro, representa um importante papel, pois tem a possibilidade de mostrar aos jovens modos de agir em que o bem-estar da sociedade seja colocado em destaque.

A escola é um dos principais locais de socialização no qual a criança ou jovem aprende não só os conteúdos teóricos acumulados na história da humanidade, mas também aprende valores como a convivência, o respeito e a valorização da diversidade. Por ser uma instituição tão central em nossa sociedade, pode favorecer em seu espaço situações em que a cooperação, a generosidade, a solidariedade e a cidadania ganhem destaque. Tais conteúdos não podem ser ensinados apenas por meio de palestras ou discussões, mas devem ser vivenciados pelos jovens para que a aprendizagem e a sua assimilação seja realmente significativa.

A escola ensina a contar, a multiplicar e dividir, ensina o nome da capital da França, os rios que atravessam o Brasil, os planetas que compõe o sistema solar (...) A escola não ensina conceitos como cortesia, compaixão, generosidade, doçura, lealdade. Ninguém discute a razão pela qual muitos filósofos consideram a coragem a mais bela das virtudes. Ninguém mais adverte aos alunos que a coragem sozinha pode se tornar perigosa se não for acompanhada de alguma outra virtude, como a solidariedade e generosidade e de uma causa justa, que beneficie a todos (CARPORALLI, 1999, p. 23 apud LIMA, 2003). 
O desenho Caverna do Dragão pode, acima de tudo, servir de inspiração para professores e coordenadores, ao pensar em estratégias de como trabalhar valores com os jovens. Os próprios dilemas apresentados aos jovens no contexto do desenho podem ser recriados no cotidiano da escola, a fim de levar os adolescentes à reflexão e, principalmente, à tomada de decisão sobre a situação apresentada. Além dos dilemas analisados neste trabalho, outros também podem ser adaptados à linguagem e à realidade dos adolescentes de hoje; mudam-se, talvez, os personagens e os cenários, mas a essência da história continua a mesma. Propor aos adolescentes que solucionem situações-problema de modo que o outro seja privilegiado surge como uma estratégia eficaz na construção da autonomia.

Os adolescentes na escola já trazem consigo um senso moral que, muitas vezes, só necessita ser despertado. Frente a uma sociedade cada vez mais competitiva, a um mercado de trabalho que privilegia os que saem na frente, a um mundo onde ninguém mais se importa com o outro, a escola pode ir na contramão e trazer para o cotidiano situações em que as virtudes apareçam e ganhem destaque. Claro que não se pode perder de vista o mundo do qual estes adolescentes já fazem parte ou irão fazer em breve, como no caso do mundo do trabalho, mas isso não significa que a escola deve aceitar e simplesmente reproduzir esta mesma sociedade em seu meio, é necessário pensar em mudanças e na transformação dos jovens por meio dos valores e da manifestação das virtudes, pois somente desta forma será possível construir uma sociedade melhor para todos.

No contexto do desenho, o grupo de amigos e a presença de figuras de autoridade, estas representadas pelo personagem Mestre dos Magos, revelam-se como aspectos importantes para o desenvolvimento cognitivo e moral de ambos. É possível apontar que os personagens somente alcançaram estágios mais amadurecidos de seu desenvolvimento quando puderam experimentar relações de trocas verdadeiras com predomínio da cooperação, nas quais se sentiram como iguais aos outros em direitos e deveres. O grupo aparece ainda como um regulador no qual os jovens visam legitimar suas ações, buscam neste a aprovação, o apoio e o respeito mútuo, fatores indispensáveis para que realizem ações mais maduras e refletidas.

No contexto escolar, as relações de amizades entre os adolescentes são, sem dúvida, um ponto que merece muita atenção por parte de professores e direção. É por meio dos amigos e destas trocas com seus pares mais próximos que os adolescentes vivenciam, de fato, a moral. As escolas, em muitos casos, tendem a reprimir e não valorizar as relações de afeto entre os jovens em seu contexto, da mesma forma que não criam espaços e momentos para que elas ocorram de modo mais significativo. $O$ professor sempre será visto pelo jovem como uma figura de autoridade, importante para o seu desenvolvimento, mas que nunca será encarado por ele como um igual, da mesma forma como ocorre com seus pais em casa. Os amigos, em contrapartida, são aqueles que estão nesta situação de igualdade e que deverão ser respeitados não porque impõem esse respeito, mas por uma necessidade cada vez mais crescente no jovem de estabelecer relações verdadeiras e ser respeitado também. 
Os amigos são aqueles com os quais se compartilham os segredos, os medos e as dificuldades, os quais se quer contar em todas as horas e momentos importantes da vida. Como ocorre no desenho, os medos e as dificuldades de cada um dos personagens serviram para despertar nos outros o sentimento de ajuda e auxílio. Cada um dos personagens teve em algum momento da série uma dificuldade que precisou enfrentar, mas, nesta hora, sempre contou com o apoio dos demais, pois a cada situação enfrentada por um, os outros também eram levados a refletir e a pensar sobre suas próprias ações.

Ao valorizar em seu ambiente tais relações de amizade entre os jovens, a escola poderá caminhar na direção de construir um local que seja cada vez mais acolhedor e receptivo, em que os jovens realmente desejam estar, pois ali estão os seus amigos e as pessoas que respeitam e admiram.

Desta forma pode-se trazer para a discussão o conceito de práticas morais, descrito por Puig (2004). Para este autor, as práticas morais são acontecimentos educacionais organizados e rotinizados que dão oportunidade aos participantes para refletirem sobre situações, exercitar o autocontrole e construir a autonomia moral.

Os educadores tendem a rotinizar as práticas escolares porque sabem que isso é imprescindível para garantir a convivência escolar e a aprendizagem [...]. Sem repetição, não há possibilidade de aprendizagem. Primeiro, porque, muitas vezes, as novas condutas ou disposições não são assimiladas senão por reiteração; e em segundo lugar, porque só vale a pena aprender aquilo que se vai repetir ou o que poderá ser aplicado de modo recorrente em situações similares (PUIG, 2004, p. 61).

Segundo o autor (2004, p. 55), “[...] as práticas escolares nos falam daquilo que os educadores e os alunos fazem em conjunto na escola [...]”. Assim, as práticas nos permitem rever conceitos que nos ajudam a entender o modo como acontece o processo de construção da moralidade em uma relação do aluno com o meio. As práticas muitas vezes são elementos utilizados pelos professores para desempenhar uma ação educativa sobre os alunos, que vão incorporando valores coletivamente elaborados. Segundo Puig (2004), as práticas morais são valores e virtudes que se convertem em comportamentos.

Para que uma prática seja efetiva, é necessário que os participantes manifestem comportamentos virtuosos. As práticas de virtude irão exigir dos sujeitos um domínio de forma excelente na incorporação de valores. Tais valores só são possíveis quando os envolvidos se dispõem a realizar os passos que darão forma à ação humana voltada para a moral.

Os personagens Mestre dos Magos e Vingador também aparecem como peças importantes para o desenvolvimento dos personagens. São estes personagens os que provocam na maioria das vezes o desequilíbrio cognitivo nos jovens e fazem surgir o conflito entre interesses, sentimentos e ideias.

O personagem Mestre dos Magos pode ser visto como o professor que auxilia o jovem em seu caminho, que o orienta quanto ao alcance de seus objetivos de vida que, no caso do desenho, envolvem o retorno para casa. Porém, este personagem nunca entrega aos jovens as respostas prontas para os enigmas, provocando sempre o pensar sobre as situações, e relatando-lhes que, a cada nova situação, será requerido deles um novo modo de pensar e enxergar o que está ocorrendo. Este personagem está presente em todos os episódios da série, mas nunca aparece como central, justamente como ocorre com 
o professor que se faz presente no contexto escolar, mas deve deixar que os alunos sejam de fato os protagonistas do dia-a-dia escolar.

Da mesma forma, é possível considerar que o personagem Vingador é quem leva os jovens ao amadurecimento, pois os obriga a sair do estágio infantil que até então se mantiveram e a buscar modos mais amadurecidos de enfrentar as situações encontradas no trajeto. Ressaltando assim a importância que os vilões ou mesmo antagonistas, desempenham em tais histórias.

Mestre dos Magos e Vingador representam na história faces diferentes de uma mesma moeda. Estes podem representar pais, professores, personalidades políticas e da mídia que servem de modelo e estimulam o jovem a se desenvolver, a construir o seu raciocínio e a pensar por si só. São os que mostram o caminho e até caminham junto, mas que não interferem naquilo que cada indivíduo faz de si mesmo e no caminho moral pelo qual escolhe seguir. Estes personagens podem levar professores e todos aqueles que estão envolvidos no processo educativo a repensar seus papéis e a propor situações em que os jovens realmente sejam desafiados a resolver situações cada vez emblemáticas.

Nesta proposta, não se pode perder de vista a multiplicidade de jovens existentes no contexto escolar. Cada jovem traz em si uma singularidade que deve ser respeitada e valorizada, e o professor, ao propor ações no contexto escolar que privilegiem a manifestação da virtude, deve valorizar esta diversidade, para que ela seja o norte que construa a autonomia e a cidadania nos jovens.

\section{Considerações finais}

O desenho analisado apresenta em seus episódios uma gama de nuances e detalhes a respeito da fase da adolescência que, na observação da vida cotidiana poderiam passar despercebidos. E mesmo tendo sido produzido no início dos anos 80, sua temática apresenta-se como bastante atual, na qual os dilemas enfrentados pelos personagens, segundo a presente análise, podem ser tomados como condizentes, em sua essência, com os enfrentados por diversos jovens contemporâneos.

O desenho aparece justamente como um retrato da vida de muitos jovens do mundo real, jovens do século vinte e um, nos quais as armas mágicas podem representar as lutas que enfrentam todos os dias. A luta contra muitos adversários, não somente gigantes ou monstros indestrutíveis, mas a luta por seus estudos, por seus trabalhos, por seus sonhos e ideias. Estes jovens lutam para permanecerem íntegros, em uma sociedade que cada vez mais parece querer corromper os indivíduos que dela fazem parte. Desta forma, é possível apontar que todo adolescente ou mesmo jovem é um grande herói do mundo contemporâneo, e que, apesar das advertências dos mais pessimistas, continua insistindo. Insiste na luta pela construção de uma sociedade na qual ele seja capaz de integrar-se livre, refletida e adequadamente, ou seja, de maneira autônoma. 
Com relação ao surgimento e manifestação das virtudes, é possível verificar que a presente discussão aponta para a coragem como uma virtude necessária à manifestação de todas as outras. Em ambos os personagens analisados é esta virtude que parece desencadear seu pensar e agir moral, aparecendo principalmente ligada ao querer agir bem, como uma força capaz de impulsioná-los na direção dos outros, e por consequência na direção de si mesmo, como indivíduos mais amadurecidos e empáticos.

No que se refere às virtudes justiça e generosidade, é possível apontar que estas figuram como aspectos da personalidade dos personagens. Porém, os jovens demonstram não ser ainda capazes de, com elas, formar um todo coeso que sirva como guia para as suas ações em todas as situações da vida. Estas virtudes aparecem nos episódios em momentos específicos e de maneira ainda pouco refletida e concretizada. Os personagens demonstram agir de modo justo ou mesmo generoso, porém isso ainda requer deles um grande esforço de abandono ao egocentrismo que configura a maneira ainda encontrada para se relacionarem com o mundo.

Há, ainda, no decorrer das ações dos personagens, o aparecimento de outras virtudes, como a gratidão, a fidelidade e o amor, que demonstram ter um importante papel de auxílio na construção e manifestação das demais virtudes ou, ainda, aparecem em resposta ao ato virtuoso, como é o caso da gratidão.

Falar na manifestação das virtudes por parte do adolescente não é algo utópico ou apenas idealizado, mas algo necessário e possível de ser realizado nos mais diferentes espaços educativos ou mesmo de socialização. As dissertações, teses e diversos artigos utilizados como referência neste trabalho apresentam exemplos de pesquisas e práticas que caminham nesta direção e mostram com entusiasmo que o trabalho de educação moral seja com crianças ou mais especificamente com adolescentes pode ser realizado.

E mesmo que na atualidade este seja um tema ainda pouco valorizado e que muitas vezes caminha na contramão das solicitações da sociedade capitalista, começa a ganhar destaque nas políticas públicas de educação. Pois, como apontado por D’Aurea-Tardeli (2007), "Para formar adolescentes empáticos, justos e respeitadores das diferenças e do meio ambiente, é preciso antes de tudo incentivar a sociedade a refletir sobre si mesma e a propiciar o diálogo coletivo" (p. 23).

A pesquisa pode revelar que a manifestação das virtudes ocorre sempre de maneira mais sutil, não estando apenas ligada a grandes atos heroicos, nos quais o que está em jogo é apenas viver ou morrer em favor de uma grande causa. As virtudes estão justamente nas pequenas ações do dia-a-dia, quando não se espera que o outro possa ser corajoso, justo, generoso, grato, fiel... Sua beleza está na sua aplicação à vida, está na surpresa despertada no outro que o leva a agir virtuosamente também, está na certeza de que passo a passo, virtude a virtude, é possível construir uma sociedade mais feliz e saudável. Está na certeza de que é possível educar crianças e adolescentes para viver nessa sociedade. 


\section{REFERÊNCIAS}

BRASIL. Estatuto da Criança e do Adolescente. Lei Federal 8.069 de 13 de Julho de 1990.

CARRAMILLO-GOING, Luana. Contos para escrever-se: alfabetização por meio dos contos de fadas folclóricos, com base em Jean Piaget e Bruno Bettelheim. 1994. 388 p. Dissertação (Mestrado em Psicologia da Saúde). Instituto Metodista de Ensino Superior. São Bernardo do Campo.

COMTE-SPONVILLE, André. Pequeno tratado das grandes virtudes. São Paulo: Martins Fontes, 1999. $225 \mathrm{p}$.

D'AUREA-TARDELI, Denise. Moral e ética - Preceitos e princípios. São Paulo: Duetto. Viver mente e cérebro - Coleção: O olhar adolescente, 2007, v. 1, n. 4. 22-29 pp.

D'AUREA-TARDELI, Denise. Solidariedade e Projeto de Vida - a construção da personalidade moral do adolescente. Campinas: Mercado de Letras, 2011. 149 p.

KOLLER, Silvia Helena. BERNARDES, Nara M. G. Desenvolvimento moral pró-social: semelhanças e diferenças entre os modelos teóricos de Eisenberg e Kohlberg. Estudos de Psicologia, 1997, v. 2, n. 1. 223-262 pp.

LA TAILLE, Yves de. Vergonha, a ferida moral. 2 ed. Petrópolis: Vozes, 2002.287 p.

LA TAILLE, Yves de. A importância da generosidade no início da gênese da moralidade na criança. Psicologia: Reflexão e Crítica, 2006a, v. 19, n. 1. 9-17 pp.

LA TAILLE, Yves de. Moral e ética: dimensões intelectuais e afetivas. Porto Alegre: Artmed, $2006 \mathrm{~b}$. $150 \mathrm{p}$.

LIMA, Anne E. O. A ética e o ensino infantil: o desenvolvimento moral na pré-escola. 2003. 154f. Dissertação (Mestrado em Educação). Universidade Estadual Paulista, Marília, SP/Brasil.

MENIN, Maria Suzana de Stefano. Desenvolvimento moral, in: MACEDO, Lino de. (org). Cinco estudos de educação moral. São Paulo: Casa do Psicólogo, 1996. 209 p. 37-104 pp.

PIAGET, Jean. O juízo moral na criança. 2 ed. São Paulo: Summus editorial, 1994. 302 p.

PUIG, Josep Maria. Práticas Morais - uma abordagem sociocultural da Educação Moral. São Paulo: Editora Moderna, 2004.

VIDIGAL, Sônia Maria Pereira. Formação da personalidade ética: as contribuições de Kohlberg e van Hiele. 2011. 143 p. Dissertação (Mestrado em Educação). Universidade de São Paulo. São Paulo. 